\title{
A supervisão na formação do analista e do psicoterapeuta psicanalítico
}

\author{
Lisiane Alvim Saraiva \\ Instituto de Ensino e Pesquisa em Psicoterapia \\ Maria Lucia Tiellet Nunes \\ Pontificia Universidade Católica do Rio Grande do Sul
}

\begin{abstract}
Resumo
Este artigo consiste na revisão sistemática da literatura brasileira sobre supervisão em psicanálise e psicoterapia psicanalítica, em periódicos científicos referenciados entre 2001 e 2006 nas bases de dados eletrônicas Lilacs, Scielo, Pepsic e Indexpsi, e localizada a partir do descritor supervisão psic \$. A busca resultou em 64 artigos, posteriormente reduzidos para 13 , em função de criteriosa leitura e descarte daqueles que não abordavam diretamente o tema. Os treze artigos foram lidos novamente e submetidos à análise de conteúdo, configurando 11 categorias de discussão. Concluiu-se que: poucos estudos que tratam do tema da supervisão assumem o formato de pesquisas empíricas; artigos não discutem os passos que supervisor e supervisionando devem seguir para atingir os objetivos desejados; as patologias na atualidade são discutidas, mas não há sugestões de mudanças na técnica e na estratégia da supervisão; poucos artigos trazem como foco o aspecto controle da supervisão; artigos com exemplos de casos não mencionam consentimento informado do paciente.
\end{abstract}

Palavras-chave: supervisão; psicanálise; psicoterapia psicanalítica; formação do psicoterapeuta

\begin{abstract}
The supervision in the training of psychoanalytical psychotherapist. The present paper is a systematic review of the Brazilian literature regarding supervision in psychoanalysis and psychoanalytical psychotherapy, in scientific journals indexed between 2001 and 2006 in the electronic databases Lilacs, Scielo, Pepsic, Indexpsi. The descriptor supervisão psic\$ led to 64 articles which were reduced for 13, after a careful examination that disregarded those in which the theme was not approached directly. The articles were reread and categorized per content analysis method. Eleven categories of discussion emerged. Results show: few studies that focused supervision were empirical researches; articles do not mention the steps that supervisor and supervisee need to follow to reach the desirable objectives; new pathologies are mentioned but there are no suggestions about technical changes in supervision strategies to deal with them; few articles mention the controlling aspect of supervision; articles that use cases as examples do not mention informed consent by the patients.
\end{abstract}

Keywords: supervision; psychoanalysis; psychoanalytical psychotherapy; psychotherapy training

$\mathrm{O}$ método da supervisão constitui um dos modelos mais antigos de ensinar e aprender um ofício, uma técnica ou uma profissão e, desde muito cedo, foi incorporado ao ensino da psicanálise, mesmo que de modo informal, sendo, posteriormente, incorporado também ao ensino da psicoterapia psicanalítica (Brito, 1999; Schestatsky, 1991). Ribeiro e Wierman (2004) salientam que, na década de 20, a supervisão foi integrada como um dos componentes da formação analítica no Instituto de Berlim, juntamente com a análise didática e o corpo teórico, constituindo, até hoje, um procedimento reconhecido da educação psicanalítica.

Assim, a supervisão é um dos três pilares básicos de toda a formação de um analista ou de um psicoterapeuta psicanalítico ${ }^{1}$, sendo considerada um dos elementos essenciais da transmissão ${ }^{2}$ da psicanálise. As outras etapas são o aprendizado teórico e o processo analítico ou psicoterapêutico (Fuks, 2002; Sieburger, 1999; Zaslavsky, Nunes, \& Eizirik, 2003).

Configurando-se em um espaço de ensino-aprendizagem e sendo uma relação bipessoal, a supervisão acaba despertando sentimentos tanto no supervisor como no supervisionando (Zaslavsky et al., 2003), caracterizando uma relação primordialmente humana, sujeita às comunicações conscientes e inconscientes (Ribeiro \& Wierman, 2004).

Fuks (2002) salienta a necessidade e pertinência da supervisão, posto que o trabalho analítico se caracteriza pela solidão, e a análise pessoal, isoladamente, não conseguiria dar conta desta necessidade de intercâmbio entre o psicoterapeuta iniciante e um colega mais experiente. Rocha (2003) pontua que 
da solidão emergem incertezas e dúvidas que colocam à prova o narcisismo do terapeuta e lança-o em busca de certezas ou garantias, quer por meio de um saber teórico, quer por meio de um saber outrem, a fim de obter respostas.

Historicamente, os supervisores são profissionais com uma bagagem experiencial significativa, que desenvolvem atividades clínicas, ou que, de alguma forma, destacam-se no trato de questões teóricas (Sieburger, 1999). São habilitados, assim, para a posição de mestres, validados pela instituição à qual pertencem por seu saber e sua experiência clínica, em condições, por sua vez, de poderem validar o trabalho do outro (Fuks, 2002).

A capacidade de continência do supervisor, sua maturidade, disponibilidade, generosidade, vitalidade e entusiasmo são fatores importantes no desenvolvimento da função psicanalítica da personalidade do supervisionando e na formação de sua identidade pessoal como analista. Cada par supervisorsupervisionando é diferente e, sendo assim, é possível haver diferentes vértices de apreensão do fenômeno clínico oferecido pelo paciente (Ribeiro \& Wierman, 2004).

Considera-se, portanto, que uma das finalidades da supervisão seja fornecer meios para que o analista desenvolva sua habilidade até o ponto em que possa, efetivamente, ajudar os seus pacientes com as mesmas técnicas básicas, variando-as conforme as necessidades de cada um (Silva, 2003). Já em 1975, Grinberg referia que um dos principais propósitos da supervisão seria conseguir que o estudante adquirisse os conhecimentos e a destreza necessários para desempenhar o mais adequadamente possível sua função como terapeuta.

A supervisão de psicoterapia também provê o aluno de feedback sobre sua performance, oferecendo-lhe possibilidades de rumos a seguir - quando se encontra em confusão ou precisando de auxílio -, permitindo-lhe a oportunidade de adquirir visões alternativas quanto à perspectiva dinâmica do paciente, intervenções e tratamento, e estimulando a curiosidade. Assim, contribui para o processo de formação da identidade terapêutica e serve de porto seguro para os supervisionandos, ao acompanhar sua aprendizagem e performance (Watkins Jr., 1997).

Souza e Teixeira (2004) buscaram identificar as percepções de psicoterapeutas e pacientes acerca das características necessárias em um bom psicoterapeuta. Concluíram que o psicoterapeuta é alguém que deve estar preparado teórica e tecnicamente e em constante aperfeiçoamento, pois se dispõe a ocupar uma posição de ajuda frente aos pacientes. Para tal, deve estar ciente da responsabilidade que abrange a sua profissão, bem como apresentar atributos, como a capacidade de ser continente, empático e estar consciente de que é necessário realizar tratamento e supervisão. Estas características podem ser desenvolvidas durante a construção da identidade do psicoterapeuta, que se dá a partir de estudos sistemáticos, prática clínica, supervisão e análise pessoal.

Esta revisão de literatura tem por objetivo geral discutir a literatura brasileira dos últimos cinco anos sobre o tema da supervisão em psicanálise e psicoterapia psicanalítica, mediante análise e categorização dos artigos selecionados nas bases de dados eletrônicas Lilacs, Scielo, Pepsic e Indexpsi.

\section{Método}

Para a consecução dos objetivos, as bases de dados Lilacs, Scielo, Pepsic e Indexpsi, foram consultadas, no intervalo dos anos de 2001 a 2006, a partir do descritor supervisão psic\$, já que o sinal \$, no site da Biblioteca Virtual em Saúde, remete a qualquer palavra iniciada pelo radical que a precede (e.g., psicoterapia, psicologia, psicanálise, psicometria, etc.), abrangendo um maior número de artigos. Trata-se de uma revisão sistemática da bibliografia de interesse: literatura brasileira sobre supervisão em psicanálise e psicoterapia psicanalítica, em periódicos científicos publicados entre os anos de 2001 e 2006.

A partir dos resumos selecionados, em um primeiro momento de acordo com a data e os descritores mencionados, obteve-se o número de 64 artigos. Fez-se uma primeira leitura destes 64 resumos, a fim de refinar a escolha dos artigos e selecionar apenas aqueles que se referiam à supervisão em psicanálise e psicoterapia psicanalítica, descartando textos da literatura não-brasileira, textos referentes à psicoterapia cognitivo-comportamental, psicoterapia humanista, textos neuropsicológicos, textos sobre construção de casos em psicopatologia e textos sobre psicodrama.

Obteve-se, então, uma redução dos 64 artigos para um número de 30 . Uma nova leitura criteriosa propiciou refinar novamente a seleção. Sendo assim, neste segundo momento, embora houvesse relação dos textos com a psicanálise, descartaram-se aqueles sobre psicologia analítica jungiana, psicologia de grupo, textos que relatavam o histórico e desenvolvimento de clínicas psicológicas, casos clínicos e textos que utilizavam a psicanálise como teoria de base para uma prática mais ampla (saúde pública, por exemplo).

Ao dar início à leitura dos 17 artigos selecionados com vista à categorização de temas emergentes nos artigos, percebeu-se que havia necessidade de uma nova seleção. Com isso, os artigos foram classificados em dois grupos: (1) os que tratavam da supervisão como objetivo do texto; e (2) os que mencionavam a supervisão secundariamente como elemento de discussão de outros objetivos relacionados, por exemplo, à formação do psicólogo, à pesquisa em psicoterapia clínica, dentre outros. Com isso, dos 17 artigos, quatro que não se enquadravam no item 1 , mas pertenciam à temática relativa ao item 2 , foram abandonados.

Portanto, a coleção final de 13 artigos, cuja essência era a supervisão como objetivo da discussão do texto, está indicada na Tabela 1. Observa-se que a maior concentração de artigos ocorreu no ano de 2003 (quatro artigos) e 2005 (três artigos). Revistas de quatro estados brasileiros foram as responsáveis pelas treze publicações estudadas: São Paulo (cinco artigos), Rio Grande do Sul (três artigos), Pernambuco (três artigos) e Rio de Janeiro (dois artigos) 
Tabela 1

Lista de artigos discutidos

\begin{tabular}{|c|c|c|c|c|}
\hline Autor(es) & Título do artigo & Periódico (Estado) & $\begin{array}{c}\text { Ano } \\
\text { Vol. }-\mathrm{N}^{\mathrm{o}}\end{array}$ & Páginas \\
\hline Neusa Sica da Rocha & $\begin{array}{l}\text { Supervisão em psicoterapia de orientação } \\
\text { analítica: a perspectiva de uma amostra de } \\
\text { supervisionados de Porto Alegre, Brasil }\end{array}$ & $\begin{array}{l}\text { Revista Brasileira de Psicoterapia } \\
\text { (RS) }\end{array}$ & $\begin{array}{l}2001 \\
\text { v. } 3-\text { n. } 3\end{array}$ & $213-227$ \\
\hline $\begin{array}{l}\text { Cleusa Kazue } \\
\text { Sakamoto }\end{array}$ & $\begin{array}{l}\text { A utilização de indicadores criativos em } \\
\text { psicoterapia breve }\end{array}$ & Psicologia Teoria e Prática (SP) & $\begin{array}{l}2001 \\
\text { v. } 3-\mathrm{n} .1\end{array}$ & $23-33$ \\
\hline Manuel José Gálvez & $\begin{array}{l}\text { Notas sobre aspectos atuais da transmissão } \\
\text { da psicanálise }\end{array}$ & Revista Brasileira de Psicanálise (PE) & $\begin{array}{l}2002 \\
\text { v.36-n.3 }\end{array}$ & $679-702$ \\
\hline Lucía Barbero Fuks & Formação e supervisão & Psicanálise e Universidade (SP) & $\begin{array}{l}2002 \\
\text { n. } 16\end{array}$ & $79-91$ \\
\hline $\begin{array}{l}\text { Jacó Zaslavsky, Maria } \\
\text { Lucia Tiellet Nunes e } \\
\text { Cláudio Laks Eizirik }\end{array}$ & $\begin{array}{l}\text { A supervisão psicanalítica: revisão e uma } \\
\text { proposta de sistematização }\end{array}$ & Revista de Psiquiatria (RS) & $\begin{array}{l}2003 \\
\text { v. } 25-\mathrm{n} .2\end{array}$ & 297-309 \\
\hline $\begin{array}{l}\text { Fernando José Barbosa } \\
\text { Rocha }\end{array}$ & Sobre a identidade do psicanalista & Revista Brasileira de Psicanálise (PE) & $\begin{array}{l}2003 \\
\text { v. } 37-\text { n. } 2 / 3\end{array}$ & $461-483$ \\
\hline $\begin{array}{l}\text { José Francisco da } \\
\text { Gama e Silva }\end{array}$ & $\begin{array}{l}\text { Comunicação e aprendizagem na supervisão } \\
\text { analítica }\end{array}$ & Cadernos de Psicanálise (RJ) & $\begin{array}{l}2003 \\
\text { v. } 19-\mathrm{n} .22\end{array}$ & $113-134$ \\
\hline $\begin{array}{l}\text { Cleusa Kazue } \\
\text { Sakamoto }\end{array}$ & $\begin{array}{l}\text { Foco e estratégia da supervisão clínica em } \\
\text { psicoterapia breve }\end{array}$ & Cadernos de Psicopedagogia (SP) & $\begin{array}{l}2003 \\
\text { v. } 2-\mathrm{n} .4\end{array}$ & $28-35$ \\
\hline $\begin{array}{l}\text { Márcia Michele de } \\
\text { Souza e Rita Petrarca } \\
\text { Teixeira }\end{array}$ & O que é ser um 'bom' psicoterapeuta? & Aletheia (RS) & $\begin{array}{l}2004 \\
\text { v. } 20\end{array}$ & $45-54$ \\
\hline $\begin{array}{l}\text { Martha Maria de } \\
\text { Moraes Ribeiro e } \\
\text { Maria Letícia Wierman }\end{array}$ & $\begin{array}{l}\text { Supervisão: exercício da função paterna em } \\
\text { psicanálise }\end{array}$ & Revista Brasileira de Psicanálise (PE) & $\begin{array}{l}2004 \\
\text { v. } 38-\mathrm{n} .1\end{array}$ & $59-76$ \\
\hline $\begin{array}{l}\text { Fernando José Barbosa } \\
\text { Rocha }\end{array}$ & $\begin{array}{l}\text { Emancipação versus adaptação: perspectivas } \\
\text { na formação psicanalítica }\end{array}$ & Jornal de Psicanálise (SP) & $\begin{array}{l}2005 \\
\text { v. } 38-\text { n. } 69\end{array}$ & $131-149$ \\
\hline $\begin{array}{l}\text { Camila Salles } \\
\text { Gonçalves }\end{array}$ & Tornar-se analista - variâncias e invariâncias & Jornal de Psicanálise (SP) & $\begin{array}{l}2005 \\
\text { v. } 38-\text { n.69 }\end{array}$ & $339-348$ \\
\hline $\begin{array}{l}\text { Maria Teresa de Melo } \\
\text { Padilha }\end{array}$ & Supervisão: o ato da palavra & Estudos de Psicanálise (RJ) & $\begin{array}{l}2005 \\
\text { n. } 28\end{array}$ & $103-110$ \\
\hline
\end{tabular}


Os 13 artigos sobre supervisão foram lidos e estudados na íntegra. Procedeu-se, então, a uma análise de conteúdo (Bardin, 1977), para o agrupamento de temas emergentes nos artigos, com a finalidade de constituir categorias temáticas amplas que possibilitassem a discussão sobre supervisão. A discussão foi realizada a partir da interlocução entre o material dos 13 artigos, ou seja, cada categoria foi discutida no interjogo de informações, postulados e discussões trazidas pelos 13 artigos analisados. Com isso, as autoras buscaram produzir uma revisão crítica distinta, no sentido de compor, através de sua ótica, a partir dos treze textos, uma espécie de $14^{\underline{o}}$ texto, um novo produto-síntese de todo o material.

\section{Apresentação e discussão das categorias}

A leitura e análise de conteúdo dos 13 artigos constelaram as categorias apresentadas e descritas conforme a Tabela 2. Cada uma delas passa a ser explicada e discutida a seguir, à luz da literatura dos próprios treze artigos analisados.

Tabela 2

Apresentação e descrição das categorias empregadas

\begin{tabular}{|c|c|}
\hline Categoria & Descrição \\
\hline 1. Histórico e definição de supervisão & $\begin{array}{l}\text { Contém informações relativas ao histórico da supervisão, bem como definições } \\
\text { conceituais. Menciona a supervisão como parte do tripé da formação, e ressalta sua } \\
\text { importância na formação da identidade psicanalítica. }\end{array}$ \\
\hline 2. Papel/função do supervisor & $\begin{array}{l}\text { Explora o papel e as funções do supervisor, elucidando as características necessárias } \\
\text { e desejadas para quem exerce tal atividade. O supervisor é percebido como modelo e } \\
\text { como terceiro no processo psicoterapêutico, garantindo um setting protetor ao jovem } \\
\text { psicoterapeuta. }\end{array}$ \\
\hline 3. Finalidade da supervisão & $\begin{array}{l}\text { Trata da finalidade e dos objetivos da supervisão, quais sejam: auxiliar o aluno em seu } \\
\text { processo de aprendizagem do ofício psicoterapêutico e monitorar os serviços prestados } \\
\text { pela instituição, através do acompanhamento do trabalho do psicoterapeuta novato, } \\
\text { garantindo a qualidade dos serviços prestados. }\end{array}$ \\
\hline 4. Impasses na supervisão & $\begin{array}{l}\text { Engloba os obstáculos que podem se fazer presente no processo de supervisão } \\
\text { e atrapalhar seu andamento, como a ocorrência de processos paralelos, fatores } \\
\text { complicadores e impasses. }\end{array}$ \\
\hline $\begin{array}{l}\text { 5. Responsabilidade do terapeuta } \\
\text { supervisionado }\end{array}$ & $\begin{array}{l}\text { Expõe aspectos referentes às características do trabalho psicoterapêutico, abordando } \\
\text { a responsabilidade do terapeuta, a necessidade de ser criativo em sua função e as } \\
\text { características desejadas em um supervisionando. }\end{array}$ \\
\hline 6. Transferência e contratransferência & $\begin{array}{l}\text { Trata destes dois fenômenos na forma como aparecem no setting psicoterapêutico e } \\
\text { como devem ser abordados em supervisão. }\end{array}$ \\
\hline 7. A utilização de casos/exemplos & $\begin{array}{l}\text { Expõe a utilização de casos como forma corriqueira de elucidar aspectos teóricos sobre } \\
\text { a temática da supervisão. }\end{array}$ \\
\hline 8. Supervisão em grupo & $\begin{array}{l}\text { Compreende as idéias e percepções acerca desta modalidade de supervisão, } \\
\text { demonstrando suas vantagens e desvantagens. }\end{array}$ \\
\hline 9. Novas patologias & $\begin{array}{l}\text { Trata das referências que apareceram em alguns textos sobre a necessidade de atentar } \\
\text { para os novos tipos de configurações patológicas que vêm surgindo na atualidade. }\end{array}$ \\
\hline 10. Supervisão de estágio & $\begin{array}{l}\text { Explora algumas características da supervisão em estágio de psicologia clínica, } \\
\text { abordando a importância de atender à demanda de urgência do paciente e à demanda } \\
\text { da formação do estagiário. }\end{array}$ \\
\hline 11. Supervisão é pouco discutida & $\begin{array}{l}\text { Discute os empecilhos que podem influenciar na não discussão mais livre da } \\
\text { supervisão, enfatizando complicações e dificuldades para a realização de pesquisas na } \\
\text { área. }\end{array}$ \\
\hline
\end{tabular}




\section{Categoria 1 - Histórico e definição de supervisão}

Rocha (2005) menciona que a prática da supervisão pode ser comprovada antes mesmo de sua institucionalização, visto que a troca de correspondências entre Freud e seus discípulos era freqüente na discussão de casos. O autor também refere que Freud cultivava o hábito de fazer longas caminhadas com aqueles que o procuravam para consultar sua opinião sobre pacientes. Oficialmente, então, a supervisão passou a fazer parte da formação psicanalítica na década de 20 , introduzida por Abraham, Eitigon e Simmel no Instituto de Berlim, sendo requisito regulamentado do processo formativo e habilitador do analista (Fuks, 2002; Ribeiro \& Wierman, 2004; Rocha, 2003; Zaslavsky et al., 2003).

Assim como a supervisão, a análise didática e os seminários e estudos teóricos configuram os pilares básicos da formação psicanalítica (Padilha, 2005; Rocha, 2005; Zaslavsky et al., 2003). Gonçalves (2005) ressalta que os componentes do famoso tripé podem ser descritos da seguinte forma: ser analisado e estar disponível para voltar a ser analisado; ter estado e estar disponível para inúmeras situações de supervisão, tanto individualmente como em grupo e participar de seminários clínicos; dedicar-se a conhecer a obra de Freud, reconhecendo-a como o ponto de partida de inúmeros outros pensadores e teóricos da Psicanálise.

Considerada um dos elementos fundamentais da transmissão psicanalítica (Fuks, 2002), a supervisão caracteriza-se pela apresentação de material clínico, relatado por um terapeuta menos experiente a um colega mais experiente, configurando uma relação de ensino-aprendizagem (Zaslavsky et al., 2003). O processo está sujeito a comunicações inconscientes e conscientes, sendo a capacidade de continência do supervisor, sua maturidade, disponibilidade, entusiasmo, etc., fatores essenciais e necessários para o desenvolvimento da formação da identidade pessoal do analista supervisionando (Ribeiro \& Wierman, 2004).

Rocha (2001) cita uma série de definições sobre o conceito de supervisão, embora não faça uma síntese própria. Menciona, então, que a supervisão é um processo complexo e um tipo essencial de processo de aprendizagem, baseado em estudo conjunto do material que descreve a interação entre o paciente e seu terapeuta. $\mathrm{O}$ analista supervisionando compartilha com um colega mais experiente os frutos de sua prática clínica, no intuito de formar uma parceria que leve ao aprendizado conjunto sobre o paciente em questão, permitindo-lhe a troca de idéias e o esclarecimento de dúvidas sobre a compreensão e o manejo do tratamento que está conduzindo.

Fuks (2002) refere que o supervisor deve atentar para o aspecto formativo do psicoterapeuta, visualizando, a partir do relato dos sintomas, discurso e história do paciente, a abordagem clínica que o aluno em formação está realizando, para auxiliá-lo e transmitir-lhe os elementos característicos do método analítico. Sakamoto (2001), ao mencionar sua experiência com supervisões de estágio em psicologia clínica, ressalta que a situação de supervisão clínica muito contribui para o estabelecimento da identidade profissional do aluno-estagiário, já que, além de atender a demanda de urgência do paciente, também atende a demanda deste "aprendiz" de psicoterapeuta. Assim, as identificações que se estabelecem entre o aluno/analista e seu analista didata, seus professores e seu supervisor formam a base da identidade do analista (Gálvez, 2002).

\section{Categoria 2 - Papel/função do supervisor}

Uma das principais funções do supervisor é auxiliar o supervisionando a tolerar a angústia do não-saber, sustentando a espera necessária para que ocorra revelação-elaboração dos processos inconscientes, sem que haja a inserção de um saber defensivo por parte do analista/supervisionando no campo. A partir da escuta, das associações do analisando e das associações do analista/supervisionando, o supervisor é capaz de indicar os movimentos a partir dos quais se deu um fechamento no processo inconsciente, sendo colocado o saber como forma de resistência. Seu papel fundamental é, portanto, ser o facilitador do reconhecimento das eventuais indiscriminações que o supervisionando possa estar vivendo (Rocha, 2003).

Zaslavsky et al. (2003) revisam as funções do supervisor em seis itens: (1) incentivar a aliança de aprendizagem; (2) manter um setting de trabalho; (3) compreender o supervisionando e fazer-se compreensível para ele; (4) identificar o conflito principal do material e formular hipóteses compreensíveis; (5) auxiliar o supervisionando a reconhecer a resistência e a transferência na interação com o paciente, bem como suas manifestações contratransferenciais; e (6) reconhecer suas próprias manifestações contratransferenciais na relação com o supervisionando.

Silva (2003) menciona que o supervisor usa como modelo de supervisão um esquema baseado na sua própria experiência de análise como paciente, nas suas experiências pessoais de supervisão e na teoria que desenvolveu ao longo de sua caminhada clínica e psicanalítica.

A construção da identidade do psicoterapeuta ou do analista sofre grande influência, portanto, dos modelos de identificação, constituídos por supervisores, teóricos e pessoas significativas em seu meio (Souza \& Teixeira, 2004). O supervisor, entretanto, não deve se colocar como um modelo a ser imitado, pois isto não auxiliaria o supervisionando a adquirir maior plenitude $\mathrm{e}$ singularidade em sua trajetória de formação (Rocha, 2005). Atitudes imitativas fazem parte do processo natural de identificação com o supervisor, mas quando estas se tornam a maioria das atitudes do supervisionando podem resultar em uma estagnação e empobrecimento do seu crescimento (Zaslavsky et al., 2003).

A supervisão também pode ser entendida como função terceira, ou seja, aquela que opera na mente do analista como função simbólica de mediação, configurando um terceiro vértice de observação da relação que ocorre entre o supervisionando e seu paciente (Resnisky, 2002, citado por Gálvez, 2002; Ribeiro \& Wierman, 2004). Ribeiro e Wierman (2004) pontuam que a função paterna em supervisão é aquela que permite a discriminação, a simbolização e o estabelecimento de um cenário analítico, no qual se efetive um distanciamento ótimo, gerando espaço para uma terceira posição, da qual se podem observar os movimentos da dupla paciente-analista. A função paterna presente na mente do supervisor propicia que se desfaçam certos conluios entre paciente e analista, reconstituindo a assimetria da 
relação e permitindo o distanciamento necessário.

Gálvez (2002) menciona, através de outros autores, o caráter protetor da supervisão, a qual pode ser compreendida como setting protetor, na medida em que protege um outro setting, que é o terapêutico, garantindo a ordem simbólica entre analista e paciente. O supervisor é, portanto, um mediador simbólico.

Rocha (2001) realizou pesquisa com o objetivo de descrever a supervisão a partir da perspectiva do supervisionando, avaliando uma amostra de residentes de psiquiatria de Porto Alegre. Entre suas conclusões, destacou o alto valor atribuído à aquisição de conhecimentos novos na supervisão, entendendo isto como um indicativo de valorização, por parte dos alunos, do momento da supervisão, além do respeito dos primeiros para com os supervisores, ao vê-los como guardiões do processo.

\section{Categoria 3 - Finalidade da supervisão}

A supervisão, por configurar uma situação de aprendizagem, também traz consigo o caráter avaliativo, sendo o supervisor um representante autorizado pela instituição a controlar e validar o trabalho de um membro mais jovem e inexperiente (Fuks, 2002). Rocha (2003) historia que, na época da fundação da Policlínica de Berlim, a supervisão passou a ser considerada como uma etapa necessária, exigência na formação do analista, com, inclusive, o poder de o supervisor, então, retirar o caso do analista estudante, tomando para si o seguimento do tratamento.

A supervisão é, portanto, um processo de habilitação do candidato, devendo o supervisor estimular, em seu supervisionando, o desenvolvimento de suas próprias habilidades - para este sentir-se seguro e ajudar os pacientes, variando suas técnicas conforme as necessidades de cada um - e a capacidade em perceber suas dificuldades (Silva, 2003; Zaslavsky et al., 2003).

\section{Categoria 4 - Impasses na supervisão}

De acordo com pesquisa de Rocha (2001), é necessário que se estudem melhor os impasses na supervisão. Os resultados obtidos, a partir dos questionários entregues a residentes de psiquiatria, indicam que áreas de interferência podem prejudicar o funcionamento do residente como terapeuta; entre elas, as respostas contratransferenciais do supervisor. Além disso, conflitos não resolvidos, relacionados à inveja, dependência, rivalidade, ao ódio e à grandiosidade, também podem ser incluídos como impasses e podem estar associados a receios dos supervisionandos, como o medo de se expor e de ser reprimido e/ou dificuldades de tolerar a ansiedade do desconhecido (Rocha, 2001; Silva, 2003).

Os textos de Gálvez (2002) e Zaslavsky et al. (2003) mencionam a questão dos processos paralelos. Estes são entendidos como a não-elaboração e compreensão da identificação projetiva do paciente pelo terapeuta, que acarreta a atuação das mesmas no espaço da supervisão. Gálvez (2002) ainda ressalta que os processos paralelos seriam as inter-relações e superposições que ocorrem entre o candidato, o paciente, o supervisor, o analista do candidato, o Instituto de Formação, etc.

Neste sentido, os conflitos na relação paciente-analista e do analista com seu próprio analista acabam por se manifestarem na relação analista-supervisor (Silva, 2003). Se a relação analistasupervisor ocorre em atmosfera emocional de confiança e respeito bilateral, a dupla envolvida poderá percorrer estes momentos de não-compreensão e ansiedade com maior tranqüilidade.

Por outro lado, se o supervisor se coloca na posição de tamponar a angústia do não-saber do supervisionando, mostrando-se como "mestre do saber" e detentor de uma versão absoluta dos fatos, pode ocorrer uma paralisação do processo analítico (Rocha, 2005). Desta feita, o analista supervisionando passa a ser destituído de sua posição de sujeito suposto saber, o que acaba por impedir o desenvolvimento do processo analítico, à medida que o supervisor assume a posição não de sujeito suposto saber, mas de saber.

Rocha (2001), em sua já citada pesquisa sobre a supervisão sob o ponto de vista do supervisionando, concluiu, a partir das respostas dos residentes ao instrumento, que a atitude mais comum adotada pelo terapeuta iniciante, quando está frente a um impasse, é buscar a ajuda de outro supervisor, um terceiro profissional. Outros mencionaram tentar conversar novamente sobre o caso com o próprio supervisor, além de estudar, ler mais e fazer uma auto-avaliação. Também os residentes relataram que as atitudes dos supervisores frente a um impasse poderiam ser dividas em empáticas e não empáticas. As empáticas englobam atitudes de acolhimento da dificuldade, apoio, procura em conjunto dos erros, revisão do caso, valorização da contratransferência do terapeuta, fornecimento de exemplos próprios, ajuda para tolerar momentos de não-compreensão e a identificação de um processo paralelo. Já nas atitudes não empáticas, foi mencionado que o supervisor se irritou ou simplesmente esqueceu o assunto.

\section{Categoria 5 - Responsabilidade do terapeuta super- visionado}

Souza e Teixeira (2004) referem que, estando no lugar de quem oferece ajuda a outras pessoas, o psicoterapeuta deve estar ciente da responsabilidade que diz respeito ao seu papel. Assim, no exercício de sua clínica, o analista em formação, a despeito do auxílio do supervisor e da troca com colegas, é o único responsável por seus atos analíticos, estando irremediavelmente só e sem garantias (Padilha, 2005; Rocha, 2003; Souza \& Teixeira, 2004).

Rocha (2001) revisa autores que tratam dos atributos ideais de um supervisionando, enfatizando que estes podem auxiliar no trabalho de supervisão. Estas características pessoais englobariam a sensatez psicológica, a abertura, a confiabilidade, o interesse, a motivação, a iniciativa, a curiosidade interpessoal, a flexibilidade e empatia em relação ao paciente, a abertura intelectual, bem como a defensividade mínima e a capacidade de introspecção. O terapeuta que esteja funcionando sob predomínio da posição esquizo-paranóide, dificilmente irá aproveitar genuinamente uma supervisão, pois a dominância da posição depressiva, ou seja, a diferenciação entre sujeito e objeto é imprescindível para a aquisição de conhecimento e para a aprendizagem (Silva, 2003).

O potencial criativo do terapeuta também é de extrema relevância, na medida em que é essencial que ocorra uma identificação integral com os propósitos terapêuticos, tanto por 
parte do paciente como do terapeuta, a fim de que, no conjunto deste envolvimento afetivo estabelecido, seja possível encontrar o potencial de construção criativo a serviço da constituição de uma nova realidade psíquica para o paciente e de desenvolvimento profissional para o terapeuta (Sakamoto, 2001).

Da mesma forma que paciente e terapeuta devem estar ligados de forma criativa, o supervisor e seu supervisionando devem formar uma dupla de investigadores que estabeleçam uma parceria criativa na apreensão do fenômeno estudado, para que novas visões da clínica sejam possíveis (Ribeiro \& Wierman, 2004). Gálvez (2002) sintetiza que a supervisão exercita a imaginação criativa do analista, a partir do paciente.

Rocha (2003) chama a atenção para o fato de que, embora o ato de transmitir leve à independência do sujeito, desenvolvendo seu potencial criativo e sua capacidade crítica em uma formação psicanalítica, deve-se ter cuidado para que este conhecimento adquirido não sirva como forma de defesa frente às angústias.

\section{Categoria 6-Transferência e contratransferência}

A transferência e a contratransferência são importantes vias de compreensão das relações de objeto e do mundo interno do paciente e se fazem presentes na relação estabelecida entre o paciente e seu psicanalista. Desta forma, este padrão estabelecido na análise pode afetar o relacionamento entre supervisor e supervisionando, à medida que o campo da supervisão é invadido por derivados do campo transferencial dos tratamentos supervisionados. Assim, identificações projetivas provenientes do paciente, quando não elaboradas e compreendidas pelo psicanalista, podem ser atuadas na relação com o supervisor, como forma de comunicação inconsciente (Zaslavsky et al., 2003).

O contexto da supervisão, portanto, deve propiciar uma aliança sólida entre o supervisor e o terapeuta, possibilitando ao supervisionando suportar as discussões detalhadas sobre a sua contratransferência (Silva, 2003). Ribeiro e Wierman (2004) referem que grande parte das angústias despertadas pela experiência vivida com os pacientes surge dos fenômenos da transferência e contratransferência e, muitas vezes, acaba emergindo no campo de continência propiciado pela supervisão.

Rocha (2005) indaga como deve proceder o supervisor face ao fenômeno da transferência na supervisão. Conclui que, por um lado, não é possível pensar o trabalho de supervisão sem o suporte de uma transferência (principalmente no que tange à confiança no supervisor escolhido); entretanto, ocorre que o supervisionando pode projetar no supervisor o seu ideal de ego, resultando em processos de idealização. Assim, segundo esse autor, espera-se que o supervisor não estimule esta transferência e que o narcisismo do supervisionando, quando depositado no supervisor, possa ser devolvido ao primeiro com "lucros".

As manifestações transferenciais, diretas ou indiretas, podem ser identificadas ao longo da sessão, durante a redação do material para supervisão ou na própria supervisão. Podem surgir dificuldades quando o supervisionando resiste em aceitar o material transferencial que lhe é comunicado pelo paciente, reproduzindo, na supervisão, o que se passa no tratamento. Também a contratransferência deve ser amplamente discutida, sendo melhor ainda se for trazida pelo supervisionando, tarefa que pode aumentar a confiança deste último no trabalho de supervisão. Caso o supervisor seja o único a se dar conta da contratransferência, sua abordagem fica mais complexa, podendo o supervisor utilizar exemplos pessoais ou indicar ao supervisionando que preste mais atenção aos seus aspectos emocionais. O supervisor também pode recomendar que aspectos pessoais sejam levados ao local mais apropriado, frisando a distinção entre supervisão e tratamento pessoal (Zaslavsky et al., 2003).

\section{Categoria 7 - A utilização de casos/exemplos}

Relatos de situações de supervisão são muito comuns, pois servem como ilustrações clínicas dos modos de se operar na supervisão. Diversos autores (Fuks, 2002; Gonçalves, 2005; Ribeiro \& Wierman, 2004; Silva, 2003), portanto, recorrem a vinhetas clínicas no intuito de exemplificar ou elucidar algum conceito, algum aspecto teórico ou alguns procedimentos e formas de conduzir a supervisão.

\section{Categoria 8-Supervisão em grupo}

A supervisão em grupo é percebida como positiva, à medida que possibilita ao supervisionando escutar relatos de diversos pacientes e ver o supervisor atuar em diferentes casos. Também possibilita ao jovem psicoterapeuta ver em ação uma série de formas de abordagem do mesmo material clínico (Fuks, 2002).

Os aspectos limitadores de se ter apenas a supervisão coletiva ou grupal em uma formação remetem diretamente à dificuldade que surge, nesta modalidade, em captar e abordar a questão da contratransferência (Fuks, 2002). Gálvez (2002) ressalta que a supervisão grupal pode ser um instrumento útil e complementar à supervisão individual.

\section{Categoria 9 - Novas patologias}

Gonçalves (2005) pontua que a questão das novas patologias enfrentadas pela clínica psicanalítica tem estado presente em inúmeras publicações, cursos e seminários. Na opinião de Rocha (2003), a pós-modernidade tem ativado os mais profundos e antigos anseios do homem, o de "tudo poder" e "tudo ter". Simultaneamente, percebe-se a intolerância a qualquer espera, ao desprazer, à frustração. Como, então, organizar a formação do analista para que possa intervir em modelos clínicos que escapam ao modelo conhecido de atendimento analítico?

O espírito dos tempos traz novos desafios, e é preciso afinar o instrumento analítico para poder detectar pedidos latentes de análises nos pacientes (Gálvez, 2002). Se, há algumas décadas, a questão das patologias psicossomáticas vem sendo objeto de importantes debates, hoje é possível ampliá-los pela inclusão das patologias do ato. Estas podem ser vistas como fruto de uma época marcada pelo narcisismo e pela ausência de lei, configurando uma sociedade permissiva na qual novas demandas surgem a todo o momento, como a questão da delinqüência, da toxicomania, da psicopatia, da adolescência prolongada e das inibições múltiplas. A questão que se coloca para reflexão, portanto, é: como a instituição psicanalítica vem acompanhando estas mutações para poder responder a tais demandas introduzidas por estas novas patologias? (Rocha, 2003). 


\section{Categoria 10 - Supervisão de estágio}

A supervisão de estágio de psicologia clínica é assunto discutido em alguns artigos. Nestes, os autores mencionam a peculiaridade do psicoterapeuta-estagiário, pois ele é aluno e enfrenta suas primeiras experiências como terapeuta, o que traz inúmeras dificuldades, já esperadas, que estão relacionadas ao preparo teórico, técnico e pessoal de seu momento profissional (Sakamoto, 2001). Neste sentido, Sakamoto (2003) discute a importância da bagagem de vida para o exercício da função terapêutica, mencionando a supervisão clínica como um trabalho fundamental, posto que considera não apenas o preparo teórico e técnico do aluno, mas também seu preparo pessoal em sua experiência como terapeuta iniciante. O estágio em psicologia clínica, portanto, congrega inúmeros propósitos que se sobrepõem e se entrelaçam: a experiência clínica do aluno, o atendimento do paciente, a supervisão do trabalho clínico que o aluno realiza, o processo terapêutico em si, a formação profissional do aluno, a dedicação e competência do supervisor.

A supervisão clínica, então, atende à demanda de urgência do paciente em seu atendimento terapêutico e, também, necessita atender à demanda relativa à formação da identidade profissional do "aprendiz" de psicoterapeuta, que é o aluno-estagiário (Sakamoto, 2001).

\section{Categoria 11 - Supervisão é pouco discutida}

Na opinião de alguns autores (Fuks, 2002; Rocha, 2001; Zaslavsky et al., 2003), a supervisão carece de maiores discussões e de estudos que a sistematizem. Rocha pontua que este é um campo que necessita ser mais bem estudado e investigado, principalmente em se tratando do supervisionando, para que haja melhor compreensão do processo de supervisão. Para Fuks (2002), a supervisão é percebida como necessária na formação de analistas, mas não é sempre e nem em qualquer local que ela é discutida com maior liberdade, para que se possam pensar quais as variantes possíveis e qual o melhor modo de inseri-la no processo formativo.

Zaslavsky et al. (2003), ao revisarem a literatura pertinente ao tema supervisão psicanalítica, concluíram que existe escassez de bibliografia específica, principalmente quando se visa focar o estudo dos fatores que influenciam o ensino e o aprendizado da técnica. Discute-se muito sobre a importância do estabelecimento de uma aliança de trabalho, quais as funções do supervisor, o referencial teórico utilizado, os traços de caráter tanto do supervisor como do supervisionando, entre outros elementos relacionados à supervisão. Entretanto, não se discute e nem se aprofunda como tais elementos podem influenciar no aprendizado da técnica, principalmente no que tange à transferência e à contratransferência.

\section{Considerações finais}

A análise criteriosa das categorias listadas, a partir do conjunto dos treze textos estudados, permite a discussão de algumas características. Primeiramente, observa-se que a maior parte dos artigos trata de aspectos teóricos relativos à supervisão. Os autores elucidam os conceitos que apresentam a partir de vinhetas clínicas de casos/exemplos, conforme observado nos artigos de Fuks (2002), Silva (2003), Ribeiro e Wierman (2004) e Gonçalves (2005). Apenas três artigos são empíricos: Rocha (2001), Sakamoto (2003), Souza e Teixeira (2004), dos quais somente o primeiro investigou a supervisão como foco. Os outros dois tratam de assuntos relacionados à experiência de estágio em psicoterapia breve (Sakamoto, 2003) e às características essenciais do exercício da psicoterapia (Souza \& Teixeira, 2004), apenas tangenciando a temática da supervisão.

Percebe-se, assim, a necessidade de mais estudos empíricos relacionados ao tema da supervisão, tendo em vista que não foi possível, para os fins deste estudo, configurar uma categoria denominada pesquisa em supervisão, já que artigos desta natureza foram raros na presente coleção estudada. Também convém lembrar que os artigos em questão pertencem a bases de dados muito utilizadas para realização de pesquisas, além de serem atuais (dos últimos cinco anos), o que demonstra que pesquisas empíricas não têm sido o foco de estudos quando se trata do tema supervisão.

Com relação à sistematização da supervisão, nas publicações investigadas, não há um conjunto de objetivos que permita ao candidato ou ao estudante saber o que dele se espera em cada uma das supervisões que realiza. Assim, alguns artigos abordam as características essenciais ao papel e função do supervisor, mencionando também as características ideais de um supervisionando; mas não discutem e nem detalham os passos que cada dupla supervisor/supervisionando deve seguir e ultrapassar para atingir os objetivos com foco na aprendizagem. Perguntar-se-ia, então, se existe uma sistematização, nas diversas instituições, na forma como a supervisão é exercida, tanto em relação aos objetivos como aos critérios de avaliação.

As patologias na atualidade são mencionadas por alguns textos (Gálvez, 2002; Gonçalves, 2005; Rocha, 2003), embora não fique claro se a supervisão deve ser modificada e, em caso positivo, que aspectos devem ser revistos, para que seja possível dar conta destas novas configurações patológicas que se apresentam nos consultórios na atualidade. Estas patologias são mencionadas como desafios, como fruto da atual sociedade e seu modus vivendi, como demandas que se apresentam para serem analisadas nos divãs e poltronas dos consultórios (Rocha, 2003). O fato é que não há, nos textos estudados que tratam sobre esta questão, discussão nem sugestão sobre modificações no método e na técnica para que seja possível lidar com estas características emergentes.

Três textos ressaltam que a supervisão não é freqüentemente discutida ou investigada: Rocha (2001), Fuks (2002) e Zaslavsky et al. (2003). Rocha (2001) e Zaslavsky et al. (2003) enfatizam que existem poucos estudos sobre a supervisão e sua sistematização, embora a supervisão seja obrigatória em todas as instituições de treinamento em psicanálise e psicoterapia psicanalítica. Zaslavsky et al. (2003) observam que pode haver dificuldades metodológicas para a concretização de tais estudos, a começar pela forma de coletar material (transcrições, gravações em áudio ou vídeo, anotações dos supervisores sobre as suas supervisões ou anotações do próprio supervisionando). Também Fuks (2002) salienta que, embora a supervisão seja aceita como necessária na formação de analistas, não se discute com liberdade sobre as variantes possíveis ou qual é o melhor modo de inseri- 
las no processo formativo. Questiona-se, portanto, se a nãodiscussão da supervisão e a não-investigação da mesma, através de pesquisas empíricas, não estariam relacionadas a relações de poder que se encontram em sua estrutura. Conforme os textos estudados demonstram, a supervisão surgiu para que houvesse um maior controle de qualidade nos serviços oferecidos pelos institutos, também, é claro, por ser parte do tripé da formação do analista. Entretanto, discute-se mais o caráter didático da supervisão do que sua função de controle. O supervisor é o elo intermediário entre o aluno em formação e a instituição, pois seu trabalho contempla necessidades de ambos os lados: deve auxiliar o aluno na sua aprendizagem e na construção de sua identidade psicanalítica, mas também deve assegurar à instituição que os novos terapeutas, que se encontram sob sua responsabilidade, estão desenvolvendo um bom trabalho com seus pacientes. Neste sentido, a supervisão envolve relações de poder, já que o supervisor está autorizado pela instituição a garantir e monitorar a qualidade dos serviços oferecidos pelos terapeutas de seu corpo clínico. Talvez seja justamente a questão das relações de poder que impeça uma discussão mais livre do aspecto controle da supervisão, ficando a maior parte dos artigos estudados centrada na questão da supervisão como função didática apenas.

Zaslavsky et al. (2003) enfatizam, portanto, as dificuldades metodológicas na realização de estudos sobre a supervisão, mencionando que um dos problemas poderia ser a coleta de material. Nos textos estudados, percebe-se que vários trazem relatos de casos como forma de ilustrar alguns aspectos da supervisão (Fuks, 2002; Gonçalves, 2005; Ribeiro \& Wierman, 2004; Silva, 2003), demonstrando, ao longo do processo, evoluções tanto do paciente como do terapeuta em formação. Nos materiais relativos a relatos de caso, não há explicitação de ter havido solicitação de assinatura de termo de consentimento livre e esclarecido para uso do material em publicação. De acordo com Teixeira e Nunes (2006), qualquer informação decorrente da relação psicoterapêutica é confidencial, a não ser que o próprio paciente autorize a sua revelação ou publicação de forma ativa. Mencionam que, a despeito da necessidade de tal tipo de escrita, para fins de ensino, o professor deve ter o cuidado de descaracterizar totalmente a identificação do paciente, preservando o sigilo das informações. Assim, a publicação de casos clínicos traz, desde a época de Freud, inúmeros questionamentos, já que o paciente não pode ser lesado de forma alguma com a publicação de material que lhe diz respeito.

Neste sentido o preenchimento de um termo de consentimento livre e esclarecido tem por objetivo proteger o paciente e garantir seu direito à privacidade, já que cabe a ele determinar quando, como e em que circunstâncias as informações poderão ser transmitidas e reveladas.

Além de toda a discussão realizada no decorrer do presente texto, dois pontos merecem especial destaque no momento de encerramento: a necessidade de mais pesquisas sobre o tema e a importância de trazer à luz as questões referentes à utilização de materiais de pacientes em publicações científicas.

\section{Referências}

Albuquerque, J. D. C. (1995). Sobre a supervisão - algumas considerações. Cadernos do Tempo Psicanalítico (Rio de Janeiro), (1), 99-104.

Bardin, L. (1977). Análise de conteúdo. Lisboa: Edições 70.

Brito, C. L. S. (1999). A transmissão do conhecimento psicanalítico através da supervisão. Dissertação de mestrado não-publicada, Pontifícia Universidade Católica do Rio Grande do Sul, Porto Alegre.

Fuks, L. B. (2002). Formação e supervisão. Psicanálise e Universidade, (16), 79-91.

Gálvez, M. J. (2002). Notas sobre aspectos atuais da transmissão da Psicanálise. Revista Brasileira de Psicanálise, 36(3), 679-702.

Gonçalves, C. S. (2005). Tornar-se analista - variâncias e invariâncias. Jornal de Psicanálise, 38(69), 339-348.

Grinberg, L. (1975). A supervisão psicanalítica: teoria e prática. Rio de Janeiro: Imago.

Padilha, M. T. de M. (2005). Supervisão: o ato da palavra. Estudos de Psicanálise, (28), 103-110.

Ribeiro, M. M. de M., \& Wierman, M. L. (2004). Supervisão: exercício da função paterna em Psicanálise. Revista Brasileira de Psicanálise, 38(1), 59-76.

Rocha, F. J. B. (2003). Sobre a identidade do psicanalista. Revista Brasileira de Psicanálise, 37(2/3), 461-483.

Rocha, F. J. B. (2005). Emancipação versus adaptação: perspectivas na formação psicanalítica. Jornal de Psicanálise, 38(69), 131-149.

Rocha, N. S. (2001). Supervisão em psicoterapia de orientação analítica: a perspectiva de uma amostra de supervisionados de Porto Alegre, Brasil. Revista Brasileira de Psicoterapia (Porto Alegre), 3(3), 213-228.

Sakamoto, C. K. (2001). A utilização de indicadores criativos em psicoterapia breve. Psicologia Teoria e Prática, 3(1), 23-34.

Sakamoto, C. K. (2003). Foco e estratégia da supervisão clínica em psicoterapia breve. Cadernos de Psicopedagogia, 2(4), 28-35.

Schestatsky, S. (1991). As intervenções do supervisor. In L. C. Mabilde (Org.), Supervisão em psiquiatria e em psicoterapia analítica (pp. 73-87). Porto Alegre: Mercado Aberto.

Sieburger, C. T. (1999). Supervisão: uma visita bibliográfica. Expressão Psi, $3(1), 67-81$.

Silva, J. F. da G. (2003). Comunicação e aprendizagem na supervisão analítica. Cadernos de Psicanálise - SPCRJ, 19(22), 113-133.

Souza, M. M., \& Teixeira, R. P. (2004). O que é ser um ‘bom' psicoterapeuta? Aletheia, 20, 45-54.

Teixeira, R. P., \& Nunes, M. L. T. (2006). O consentimento informado em psicoterapia como evidência ética. In B. S. G. Werlang \& M. S. Oliveira (Orgs.), Temas em psicologia clínica (pp. 47-54). Porto Alegre: Casa do Psicólogo.

Valabrega, J. P. (1983). A formação do psicanalista. São Paulo: Martins Fontes.

Watkins Jr., C. E. (1997). Handbook of psychotherapy supervision. Hoboken, New Jersey: Wiley.

Zaslavsky, J., Nunes, M. L. T., \& Eizirik, C. L. (2003). A supervisão psicanalítica: revisão e uma proposta de sistematização. Revista de Psiquiatria do RS, 25(2), 297-309. 
${ }^{1}$ As designações analista ou psicoterapeuta psicanalítico serão mantidas neste texto de acordo com a utilização de um ou outro termo pelos respectivos autores citados. A formação de um analista ou de um psicoterapeuta psicanalítico é similar, visto que ambas têm como embasamento o estudo teórico da Psicanálise, a prática supervisionada e o tratamento pessoal.

${ }^{2}$ Adotar-se-á a palavra transmissão, que é citada por diversos autores (Albuquerque, 1995; Fuks, 2002; Padilha, 2005; Rocha, 2003; Valabrega, 1983; entre outros), para designar o ato de ensino da Psicanálise. Segundo Rocha (2003), a transmissão da Psicanálise se dá, essencialmente, por meio da experiência analítica além da via privilegiada da análise pessoal, da supervisão e do conhecimento dos pilares fundadores da teoria psicanalítica. Já Padilha (2005) menciona que aquilo que se transmite não se ensina.

Lisiane Alvim Saraiva, mestre em psicologia clínica pela Pontifícia Universidade Católica do Rio Grande do Sul, é coordenadora da Comissão de Pesquisa do Instituto de Ensino e Pesquisa em Psicoterapia. Endereço para correspondência: Rua Grão Pará, 95 Ap. 303; Porto Alegre, RS; CEP: 90850-170. Telefones: (51) 3233-7472 / (51) 9968-6626. E-mail: lisianesaraiva@hotmail.com

Maria Lucia Tiellet Nunes, doutora em Psicologia pela Universidade Livre de Berlim, é professora e coordenadora do Programa de Pós-graduação em Psicologia da Pontifícia Universidade Católica do Rio Grande do Sul. E-mail: tiellet@pucrs.br 